\title{
Optimizing the Distribution System of Fast Moving Consumer Goods Company Using Sweeping Methods with Discrete Event Simulation Approach
}

\author{
Arry Rahmawan D. ${ }^{1}$, Bhagas Aufa H. ${ }^{1}$, Fairuz Qalbi A. ${ }^{1}$, Satrio Nur K. ${ }^{1}$, Bagas Brahmantyo ${ }^{1}$ \\ ${ }^{1}$ Department of Industrial Engineering, Universitas Indonesia, Depok, West Java, Indonesi
}

\begin{abstract}
FMCG is considered as one of the industry with the highest competition in the world. To win this industry, customer satisfaction becomes the main thing. In this paper, authors will simulate a system of distribution of goods from PT X TBK which has 3 categories, namely M1 (biscuit), M2 (powder) and M3 (liquid). The distribution system has a problem on time delivery of goods which have a wide variety of obstacles, mainly on routing. There are 8 trucks with different routes and different utilization. There's trucks with over hour work and trucks with long idle time. The routing also causes problem for unused truck weight and volume capacity, where cost could possibly be reduced. Through Discrete event simulation and sweeping method, authors try to solve the problem by modelling the existing system and then find the solution to improve the distribution system and reaching the model objective.
\end{abstract}

\section{Introduction}

Logistics management is that part of supply chain management that plans, implements, and controls the efficient, effective forward and reverse flow and storage of goods, services and related information between the point of origin and the point of consumption in order to meet customers' requirements. (Council of Supply Chain Management, 2014)

PT X TBK is one of the consumer products company in Indonesia, focused in packaged foods. Packaged foods industry is one of the industries with biggest market in Indonesia. The transaction volume of the packaged food in 2015 reached 6 million Tons and according to Indonesia-Investment, in Quarter 1 year 2016, packaged foods sales already reached IDR 400 trillion. With the growing GDP and population in Indonesia (about 250 million people, the $4^{\text {th }}$ biggest in the world), Indonesia is without a doubt an interesting market for packaged food Industry. (Euromonitor International, 2016)

To win this industry, one of the key factors is the capability to reach and keep the customer. Hereby, supply chain and logistic will be one of the determinant factor for PT X to achieve them. The purpose of the logistic system is how to deliver the products to consumer with the lowest cost possible. Logistic function in $\mathrm{PT} \mathrm{X}$ is involving several third parties. One of the partners is PT Y Distribution. This company has a partnership with PT X to distribute PT X's product in Depok, West Java areas. The planned process by PT Y Distribution is they distribute the products based on the category that they've made, consist of M1, M2, and M3 (M1 for snack products, M2 for powder products, and M3 for liquid products). But, this distribution system is facing several problems that are mainly caused by the routing, where the usage of resources is not balanced. There's a route where a truck could finish their delivery far before its shift ends while still having unused space in it's box, wasting its weight and volume capacity. In the same day, there's a route where a truck must work overtime to finish its delivery, arriving very late at the headquarter warehouse and causing the worker to went home late, feeling more tired than others. The same route also causes some of the customer stores receive the delivery late.

In this paper, authors are not only making a model about the actual condition, but also displays methodology using Discrete Event Model and Sweeping Method that will improve the distribution routes, where truck as the main resources is utilized more efficiently by usage time, volume, and weight capacity to create a balanced work load for each worker, enhance delivery on time, and reducing the total cost for PT Y Distribution.

\section{Literature review}

This project is closely related to the Time-Dependent Dynamic Vehicle Routing Problem that reflects varying traffic conditions and also considers carbon emission, fuel and time efficiency of vehicles. The Time-Dependent Vehicle Routing Problem has been introduced to solve problem in a traffic network. A mixed integer formulation of the time-dependent vehicle routing problem where the travel time on each arc is a step function of the departure time was proposed (Daskin, 1992). Several years later, this routing problem improved by anticipating the potential 
value by considering path changing in the Dynamic Vehicle Routing Problem.

Research of Dynamic Vehicle Routing Problem has been an interesting subject for many years until now. The Green Time-Dependent Routing, which consider vehicle routing problem to minimize emissions (Jan Fabian Ehmke, 2015). They investigated how to simplify the precomputation of emission-minimizing paths by identifying the optimal paths that are independent of the vehicle load and used a tabu search method to solve the routing problem. Their test instances are based on a large real road network and extensive experiments are tested for analysis. On the same year, used a fuzzy ant colony system to solve the dynamic vehicle routing problem with uncertain service time. A fuzzy ant colony system uses the cluster insertion algorithm to divide customers. This algorithm groups the customers into several small clusters based on the distance between customers. The routes between customers within a cluster have higher pheromone levels than routes between customers in two different clusters. Besides, a vehicle tends to serve customers within the same cluster. Newly arrived customers are assigned to the nearest cluster. (Kuo, 2016)

From this literature, authors make four main sections to be reviewed. The first one is about what is the literature about, and then what the problem is, how the authors save it, and the conclusion about the problem and all things about the literature. This literature is all about comparing two modeling approaches to help people solve about logistics and supply chain management (LSCM) problems. Discrete event simulation (DES) is one out of a two modeling approaches used by this literature. It's widely used as decision support tools in LSCM. DES is used at an operational/tactical level. This paper explores the application of DES as decision support systems (DSS) for LSCM by looking at the nature and level of issues modeled. The authors findings suggest that DES has been used more frequently to model supply chains than the system dynamics one (modeling approaches that used in this literature).

This research is about PT Y Distribution's Distribution and logistic systems route around Depok, West Java Area. The solution can be gained by using DES, because the problem is more of operational/tactical level issues. Authors could use SD to model it or give some solution to solve the problem, but the DES could give more choices of solution.

(Nurcahyo, 2002) used as the main basis to solve routing problem. Sweep Algorithm consist of two stages. Stage 1 is called clustering stage, it illustrates a clustering process of several nodes and sweep hand that moves counter-clockwise. Clustering performed by joining nodes, beginning from the closest node to any node that is chosen to be the first node. The closest node is the one that has smallest angle. This process is repeated by joining the rest of the nodes until it satisfies the constraints. Stage 2 is called route generation. The objective of this stage is to link all nodes in every cluster of path network.

From all of the papers mentioned above, authors found novelty as it combines the Discrete Event Simulation with Sweep Algorithm. The real situation could be modeled with Discrete Event Model and use Sweep Algorithm as the main basis to find a better routing. Then, the Discrete Event Simulation is used to check the result and find other possible solutions.

\section{Research method}

There are some steps to doing the research and modeling the simulation for getting a great implementation in the end.

\subsection{Research background}

PT Y Distribution applies the take-order system, where there's salesman that visit customer stores using motorcycle. They take orders from the customers and bring them back to headquarter. The Headquarter then would plan a delivery system for the next day.

In the field, product distribution activities are always facing various problems that mainly caused by the routing, where the usage of resources is not balanced. There's a route where a truck could finish their delivery far before its shift ends while still having unused space in its box, and there's a route where a truck must work overtime to finish its delivery, arriving very late at the headquarter warehouse. The same route also causes some of the customer stores receive the delivery late. The biggest sales is happening on Wednesday, causing the number of products to be delivered reach its peak on Thursday. This day also has the largest distribution cost compared to other days. So, the research would focus on Thursday because it would give the biggest Impact for the stakeholder.

Table. 1 describes the product sales PT X in Depok for a week starting from 28 November 2016 to 3 December 2016. The table describes the number of stores visited by the delivery trucks to deliver products PT X. According to distribution mechanism by PT Y Distribution, the orders taken today will be delivered on the next day.

Table 1. Product sales, number of stores, and delivery cost

\begin{tabular}{|c|c|c|c|c|c|c|}
\hline Day & M1 & M2 & M3 & $\begin{array}{c}\text { Total } \\
\text { Product } \\
\text { Per } \\
\text { Day }\end{array}$ & $\begin{array}{c}\text { Number } \\
\text { of } \\
\text { Stores }\end{array}$ & $\begin{array}{c}\text { Delivery } \\
\text { Cost }(\text { Rp })\end{array}$ \\
\hline Monday & 834 & 365 & 1615 & 2814 & 114 & 1.865 .009 \\
\hline Tuesday & 751 & 551 & 1755 & 3027 & 75 & 1.672 .778 \\
\hline Wednesday & 1008 & 563 & 1931 & 3502 & 92 & 1.896 .566 \\
\hline Thursday & 975 & 422 & 1584 & 2981 & 134 & 2.521 .327 \\
\hline Friday & 789 & 332 & 1446 & 2567 & 67 & 1.924 .553 \\
\hline Saturday & 896 & 447 & 1540 & 2883 & 34 & 1.108 .896 \\
\hline
\end{tabular}

It also describes the costs incurred by $\mathrm{PT} Y$ Distribution PT $\mathrm{X}$ in trucking the products to the stores according to order during the week from 28 November 2016 until December 3, 2016.

\subsection{Problem definition}

From the background that has been explained, there are 3 main problems: 
1) The weight and volume capacity of the truck is not optimal yet, there's still trucks with many unused space in weight and volume capacity in their distribution

2) There's still truck that has to do overwork to finish their delivery, causing the worker to come late to the headquarter and feel more tired than others

3) There's still stores that didn't get the delivery on time (by 5PM according to the salesman deal).

\subsection{Objectives}

Based on the observations made directly in the field, as well as supporting data from the company, there are four objectives which authors will achieve through the solution from the model. The Model Objectives are:

1) Reducing total unused trucks volume and weight capacity by $50 \%$

2) Ensure that $100 \%$ truck finished their delivery without doing overwork and could get back to headquarter on time

3) Ensure that $100 \%$ stores could get the delivery on time (by $5 \mathrm{PM}$ according to the salesman deal)

4) Reducing total cost by $20 \%$ :

\section{The model}

The Model was constructed by using actual observation on the day that the delivery actually happened. Table 2 . Shows the components in constructing our model.

\subsection{Model construction}

Table 2. Model Components

\begin{tabular}{|l|c|}
\hline Location & Store $1-134$, warehouse \\
\hline Entitiy & The Products (M1,M2,M3) \\
\hline Resource & Truck $1-8$ (Ankle and Double) \\
\hline Simulation Time & $09.00-17.00$ (one work day) \\
\hline Shift & $\begin{array}{c}09.00-17.00 \\
\text { (Break in } 12.00-13.00 \text { for lunch) }\end{array}$ \\
\hline Path Network & Truck Route $1-8$ \\
\hline
\end{tabular}

\subsection{Model equations}

There are some key equations to help authors achieve the model's goals:

1) Moving Time

$\mathrm{TW}=$ Truck Weight

$\mathrm{TW}=$ Standard Truck Weigh (5500)

$$
M T=\frac{\sum \text { Distance }}{\text { Speed }}
$$

2) Volume Capacity

$$
0,036 M 1+0,033 M 2+0,01 M 3 \leq 11,628
$$
(Ankle truck)

$$
\begin{aligned}
& \text { 0,036M1+0,033M2+0,01M3 } \leq 21,5 \\
& \text { (Double truck) }
\end{aligned}
$$

\section{i. $\quad$ Truck Utilization}

(4)

$$
T U=(\text { Time Used }) /(\text { Time Available })
$$

$$
\text { ii. Weight Capacity }
$$

$$
\begin{aligned}
& 2 M 1+4 M 2+10 M 3 \leq 4000 \\
& (\text { Ankle truck }) \\
& 2 M 1+4 M 2+10 M 3 \leq 6000
\end{aligned}
$$$$
\text { (Double truck) }
$$

$$
\begin{gathered}
\text { iii. } \quad \text { Total Cost } \\
T C=\text { Driver Cost }+F C \\
\text { iv. Fuel Cost }
\end{gathered}
$$

3) Fuel Consumption (100 Km)

$$
\frac{T W-\overline{T W}}{100} \times 0,5+25
$$

A recent study found that for every $100-\mathrm{kg}$ reduction, the combined city/highway fuel consumption could decrease by about $0.4 \mathrm{~L} / 100 \mathrm{~km}$ for cars and about 0.5 L/100 km for light trucks (MIT 2008).

\subsection{Model scenarios}

This model is run with 2 kinds of scenarios. The first scenario is based on the real data, while the second scenario is modeling the distribution system in a heavy rain condition.

\subsection{Verification and validation}

Validation techniques has two step. First is model conceptualization validation and the second is model validation. In model conceptualization validation, the research team use face validity by asking feedbacks from our stakeholder, which is the distribution manager in PT. $Y$ Distribution. In model validation, the research team used extreme condition test and sensitivity test. The model is also verified by face verification, asking for feedbacks one more time after the model is done. The feedbacks are positive and the stakeholder is pleased.

\section{Results and discussion}

\subsection{Model construction}

Table 3. Scenario Result

\begin{tabular}{|c|c|c|c|c|c|c|}
\hline & Utiliz & Work & Late & Unuse & Unuse & Total \\
& - & Overti & Deli & $d$ & $d$ & Cost \\
& ation & me & Volum & Weigh & $(R p)$ \\
\hline
\end{tabular}




\begin{tabular}{|l|c|c|c|c|c|c|}
$\begin{array}{l}\text { Scenari } \\
\text { o 1 }\end{array}$ & $\begin{array}{c}61.53 \\
\%\end{array}$ & 1 & 0 & 55.9 & 16422 & $\begin{array}{c}2.481 .0 \\
12\end{array}$ \\
\hline $\begin{array}{l}\text { Scenari } \\
\text { o 2 }\end{array}$ & $\begin{array}{c}84.48 \\
\%\end{array}$ & 5 & 16 & 55.9 & 16422 & $\begin{array}{c}2.481 .0 \\
12\end{array}$ \\
\hline
\end{tabular}

Table 3. shows the result of model on the real data scenario. The utilization is achieved from the equation that mentioned before. The work overtime defined as a truck that hasn't been back to the warehouse in $5 \mathrm{PM}$. The late deliveries defined as number of stores that hasn't get their deliveries in $5 \mathrm{PM}$. The $5 \mathrm{PM}$ parameter is from the deal that salesman make with the stores when they sales the products. Authors also got the unused volume, weight, and total cost from the equation that mentioned before. The result found that there is a room for improvement, where the unused volume and weight is really high in number while the utilization is not really high. It is also seen there's still a truck that has to work overtime to finish their job while the others don't. This result can be used as main base to later generate alternative solutions.

\subsection{The heavy rain scenario result}

On the heavy rain scenario, the speed of truck is dropped and the pickup and deposit time is doubled. Compared to the real data scenario, it is seen that there's a significant increase in the number of trucks that has to work overtime and the late deliveries.

Table 4. Solution Implementation

\begin{tabular}{|l|c|}
\hline & Result in Scenario 2 \\
\hline Utilization & $86.89 \%$ \\
\hline Work Overtime & 3 \\
\hline Late Deliveries & 23 \\
\hline Unused Volume (m3) & 22.8 \\
\hline Unused Weight(kg) & 6422 \\
\hline Total Cost (Rp) & 1.762 .067 \\
\hline
\end{tabular}

\subsection{Generating solution}

From the result that mentioned above, authors did a brainstorming with the help of fishbone tool. This tool is used to find the root cause in this distribution problems so that authors could generate alternative solutions. It is decided that the root cause is in the methods. There's 2 methods that could be improved. First, the routing. The current routing didn't consider the truck capacity, resulting in great number of unused truck capacity. The second one is the products layout method in the truck box. The products is put randomly as fast as possible when the truck is doing pickup at the warehouse, resulting in long searching time when they did the delivery in each stores, they have to match the specific demand with the randomly-put products in the truck. From those root causes, authors propose 3 alternative solutions:

1) Use the sweeping method in order to determine a better distribution route that has considered truck capacity
2) Spend more time in pickup at the warehouse, where the workers put the products following the stores demand that has been ordered according to the route.

3) The combination of solution 1 and 2

\subsubsection{Solutions Implementation at the real data scenario model}

Table 5. Heavy Rain Scenario result

\begin{tabular}{|l|c|c|c|c|}
\hline & Real & $\begin{array}{c}\text { Solution } \\
1\end{array}$ & $\begin{array}{c}\text { Solution } \\
2\end{array}$ & $\begin{array}{c}\text { Solution } \\
3\end{array}$ \\
\hline Utilization & $61.53 \%$ & $66.63 \%$ & $62.72 \%$ & $64.43 \%$ \\
\hline $\begin{array}{l}\text { Work } \\
\text { Overtime }\end{array}$ & 1 & 0 & 0 & 0 \\
\hline $\begin{array}{l}\text { Late } \\
\text { Deliveries }\end{array}$ & 0 & 0 & 0 & 0 \\
\hline $\begin{array}{l}\text { Unused } \\
\text { Volume } \\
\text { (m3) }\end{array}$ & 55.9 & 22.8 & 55.9 & 22.8 \\
\hline $\begin{array}{l}\text { Unused } \\
\text { Weight } \\
\text { (kg) }\end{array}$ & 16422 & 6442 & 16422 & 6442 \\
\hline $\begin{array}{l}\text { Total Cost } \\
\text { (Rp) }\end{array}$ & 2.481 .012 & 1.762 .067 & 2.481 .012 & 1.762 .067 \\
\hline
\end{tabular}

In Solution 1, the sweeping method is used to create a new route, authors did a counter clockwise stores grouping based on shortest distance between stores and the truck capacity. The new truck only used if the demand in the stores group couldn't fit in anymore with the truck volume or weight capacity. From the Sweeping Method, authors create a new path network for each of the trucks in the model. The result is the trucks could accomplish zero work overtime and late deliveries by only using 6 trucks. Then, authors eliminate one Ankle and one Double because according to our stakeholders, both of them actually a backup trucks that only used if the deliveries in the day couldn't be accomplished by normal amount of trucks. By this model, it is proved that instead of 8 trucks, 6 trucks could maintain the utilization, accomplish zero work overtime and late deliveries, reducing unused volume and weight, and reducing total cost.

In solution 2, it is assumed that the pickup time at the warehouse would increase 30 minutes because the workers have to put the products in order according to the stores demand that has been ordered along the route. But, the benefit is assumed that the deposit time in each store would decrease $25 \%$ because the reduced searching time. The result is there's zero work overtime and late deliveries, but, the unused truck capacity remains the same because there's no change in the route and the amount of trucks.

In solution 3, authors combine both of solution 1 and 2 . The new route is used using sweeping method and gave the better product layout within the trucks. The result shows that this solution is the best one, because it gives the same improvement with solution 1 with lower utilization, meaning that in solution 3 , the trucks could accomplish the task faster than in solution 1. So, it is recommended that solution 3 could improve the system. 


\subsubsection{Solutions Implementation at the Heavy Rain Scenario}

Table 6. Solution implementation on heavy rain scenario

\begin{tabular}{|l|c|c|c|c|}
\hline & Real & Solution 1 & Solution 2 & Solution 3 \\
\hline Utilization & $86.89 \%$ & $74.4 \%$ & $79.01 \%$ & $64.08 \%$ \\
\hline $\begin{array}{l}\text { Work } \\
\text { Overtime }\end{array}$ & 3 & 2 & 3 & 0 \\
\hline $\begin{array}{l}\text { Late } \\
\text { Deliveries }\end{array}$ & 23 & 0 & 6 & 0 \\
\hline $\begin{array}{l}\text { Unused } \\
\text { Volume (m3) }\end{array}$ & 22.8 & 22.8 & 22.8 & 22.8 \\
\hline $\begin{array}{l}\text { Unused } \\
\text { Weight } \\
\text { (kg) }\end{array}$ & 6442 & 6442 & 6442 & 6442 \\
\hline $\begin{array}{l}\text { Total Cost } \\
\text { (Rp) }\end{array}$ & 1.762 .067 & 2.587 .067 & 1.962 .067 & 2.787 .067 \\
\hline
\end{tabular}

After choose the best solution, authors applied the solution into heavy rain scenario model to see if the goals could also be accomplished in the worst condition or not. The result is shown at the table above. The result is pretty disappointing because even though the decrease of unused volume, weight, and total cost meet the same accomplishment, the percentage of work overtime and the amount of late deliveries is increased.

So, authors went back to brainstorming phase to find new alternative solutions that could be applied in the new model using solution 3 in heavy rain scenario. It is found that the root cause of the long-deposit time is that the workers has to wait until the rain is slowing down and then use an umbrella when doing the delivery in each store because they afraid that if the products get wet, the cardboard would be damaged and the stores would reject the products, causing lost profits for the firm. So, based on that root cause, our team propose 3 alternative solutions to improve the distribution system of PT Y Distribution in heavy rain scenario:

1) Hire one more worker to help with the distribution to fasten the deposit time

2) Buys a raincoat for the workers and a large plastic to cover the products when they did the deliveries

3) The combination of solution one and two

The table below (Table. 7) highlights the result of each alternative solutions.

In solution 1, the company hire one more worker to help fasten the deliveries. The deposit system that the workers applied is that one person stack the products in the truck box so that one more person could bring the stack in one go. It is assumed that by adding one more person to bring the stack could reduce the deposit time by $40 \%$ because the time needed to stack the product is far lower than the time needed to bring the stack. So, by doing this, the idle time could be reduced for the worker that only stack the products. The result is pretty satisfying because the number of late deliveries is reduced to zero. But, there's still trucks that has to work overtime to accomplish that. The cost is rather high because the driver (worker) cost is increased $150 \%$ by adding one more person.

In solution 2 , the company would buy a raincoat for all of the workers and a very large plastic to cover the stacked products when it's being delivered in each stores. It is assumed by doing this, the deposit time could be reduced by $20 \%$ because they didn't have to wait for the rain becomes lighter and they didn't have to use umbrella anymore where the products that could be brought in one go is smaller in amount than our alternative solution. It is seen that the result is not as good as solution one because there's still 6 late deliveries and the number of work overtime is also bigger. But, it's cheaper because buying raincoat and plastic only cost Rp.200.000 and it last for a long time, could be used for a lot of deliveries.

In solution 3, authors combined both solution 1 and 2 , which are add one more workers and bought raincoat and plastic to help fasten the deliveries. By doing this, the company could accomplish zero late deliveries and work overtime. The threat off is this solution has the biggest cost among all of the solutions. In the end, it is recommended that solution 3 could be implemented because the utilization is the lowest among all, meaning that it's the fastest to finish the deliveries. The "bonus time" could be used as anticipation if the rain is really heavy and the delivery time becomes longer than our scenario. To show our overall research goal achievement, authors put all of the improvement results in scenario 1 and scenario 2 in the table below. It is seen that all of the research goals are achieved in both scenarios, except reducing $20 \%$ cost in scenario 2 . From the research, it is decided that in order to achieve other important goals, an extra cost would be needed. 
Table 7. Result of Each Alternative Solutions

\begin{tabular}{|l|c|c|c|c|c|c|c|}
\hline & \multicolumn{3}{|c|}{ Scenario 1 } & \multicolumn{4}{c|}{ Scenario 2 } \\
\cline { 2 - 8 } & Before & $\begin{array}{c}\text { Final } \\
\text { Improvement }\end{array}$ & $\begin{array}{c}\text { Research } \\
\text { Goal }\end{array}$ & Before & $\begin{array}{c}\text { First } \\
\text { Improvement }\end{array}$ & $\begin{array}{c}\text { Final } \\
\text { Improvement }\end{array}$ & $\begin{array}{c}\text { Research } \\
\text { Goal }\end{array}$ \\
\hline Utilization & $61.53 \%$ & $64.43 \%$ & & $84.48 \%$ & $86.89 \%$ & $64.08 \%$ & \\
\hline $\begin{array}{l}\text { Work } \\
\text { Overtime }\end{array}$ & 1 & 0 & $\mathrm{v}$ & 5 & 3 & 0 & $\mathrm{v}$ \\
\hline $\begin{array}{l}\text { Late } \\
\text { Deliveries }\end{array}$ & 0 & 0 & $\mathrm{v}$ & 16 & 23 & 0 & $\mathrm{v}$ \\
\hline $\begin{array}{l}\text { Unused } \\
\text { Volume (m3) }\end{array}$ & 55.9 & 22.8 & $\mathrm{v}$ & 55.9 & 22.8 & 22.8 & $\mathrm{v}$ \\
\hline $\begin{array}{l}\text { Unused } \\
\text { Weight(kg) }\end{array}$ & 16422 & 6442 & $\mathrm{v}$ & 16422 & 6442 & 6442 & $\mathrm{v}$ \\
\hline $\begin{array}{l}\text { Total Cost } \\
\text { (Rp) }\end{array}$ & 2481.012 & 1.762 .067 & $\mathrm{v}$ & 2.481 .012 & 1.762 .067 & 2.787 .067 & $\mathrm{x}$ \\
\hline
\end{tabular}

This research shows that Discrete-Event Simulation (DES) performed preferable solutions than System Dynamic (SD). It is because DES Modeling solutions provide greater number of calculations at the individual level while SD has minimal data requirements to build a model. Dynamic Vehicle Routing Problem (DVRP) is one of System Dynamic example. In different point of solutions, Discrete-Event Simulation supports Sweep Algorithm Method to generate a new alternative solution by represent the result of Algorithm in a modeling simulation.

Sweep Algorithm have divided locations equally rather than fuzzy ant colony in Dynamic Vehicle Routing because each cluster has a large different number of locations. It also has more detailed variables of observation. Authors are not only observe the use of the transportation but also count the total cost for the solution and the net profit gained from the model. It is also count the cost of the driver, the fuel, the products production, the weight, the volume and else, so that the company could choose the better solution. Nonetheless, real-life situations may not be totally performed as the model assumes several constant rates and uncertain distributions.

\section{Conclusion and Suggestion}

After doing research, it can be concluded that the unbalance use of resources which caused overtime for many workers can be solved by the use of Sweep Algorithm combined with Discrete-Event Simulation and put the products following the stores demand that has been ordered according to the route to match the resource utilization and improve the customer's satisfaction. Our research provides 2 types of scenario, the first one shows the original condition and the second one shows the first scenario that face the rainy weather disturbances.

Having performed at Pro-Model simulation using the sweeping method, the use of 6 trucks can still be utilized better because capacity utilization is still low. If used properly, it will increase sales and profit targets obtained will also be more. For the first scenario, the most suitable solution is build the new route using sweeping method and make a better product layout within the trucks.. Then, for the second scenario the most suitable solution is add more workers and bought the raincoat and plastic to fasten the delivery. These solutions can reduce the total unused trucks capacity by $50 \%$, ensure that trucks finished their total delivery without being late in every stores by $100 \%$, and reduce the total cost by $20 \%$ in scenario 1 . In scenario 2 , the firm have to pay more to add workers and buy the plastic and raincoat as its best solution. However, the usage of assumptions and limitations for Discrete-Event Modeling in Pro-model need to be minimized to get the clearer data. The calculation of distances between locations in Pro-model can also be developed to obtain more specific scale

\section{References}

1. Nurcahyo, Gunadi W et all. 2002. Sweep Algorithm in Vehicle Routing Problem For Public Transport. Jurnal Antarabangsa (Teknologi Maklumat) 2(2002): 51-64

2. Malandraki, C and Daskin, M. 1992. Time Dependent Vehicle Routing Problems: Formulations, Properties and Heuristic Algorithms. Transportation Science 26(3):185-200

3. A.A Tako, S. Robinson. 2002. The application of discrete event simulation and system dynamics in the logistics and supply chain context. Decision Support Systems, Vol 52, pp. 802-815

4. Ahmadi, Mansour. 2012. The application of system dynamics and discrete event simulation in supply chain management of Swedish manufacturing industries. Product and Process Development Innovative Product

5. B. Angerhofer and M. Angelides. 2000. 2000 Winter Simulation Conference, pp. 342-351.

6. L. F. Cheng and M. A. Duran. 2004. Logistics for world-wide crude oil transportation using discrete event simulation and optimal control. Computers \& Chemical Engineering, vol. 28, pp. 897-911

7. Huang, Yixiao. 2016. Time-dependent vehicle routing problem with path flexibility. Transportation Research Part B 95 (2017) 169-195

8. Kuo, R.J. 2016. Application of a fuzzy ant colony system to solve the dynamic vehicle routing problem 
with uncertain service time. Applied Mathematical Modelling 40 (2016) 9990-10 001

9. Arifin, Aridhanyati. 2014. Model transportasi untuk masalah pendistribusian air minum (studi kasus pdam surakarta). TEKNOMATIKA Vol. 7, No. 1, JULI 2014

10. Wassan, Niaz A et al. Vehicle Routing Problem with Deliveries and Pickups: Modelling Issues and Metaheuristics Solution Approaches. International Journal of Transportation

11. Council of Supply Chain Management. Cscmp.org. Web. 10 Nov 2016

12. Euromonitor International. Euromonitor.com. Web. 10 Nov 2016 